\title{
The Pinealocyte Forming Receptor and Effector Endings: Immunoelectron Microscopy and Calcium Histochemistry*
}

\author{
Béla VigH and Ingeborg Vigh-TeichmanN \\ 2nd Department of Anatomy, Histology and Embryology, Semmelweis University Medical School and Neuroendocrine Labora- \\ tory, Hungarian Academy of Sciences-Semmelweis University Medical School Joint Research Organization, Budapest, Hungary
}

Summary. The pinealocytes-the main cellular elements of the pineal organ-are polarized, displaying a (photo)receptor and an axonic effector cell pole. The receptor endings are of two main types: they bear rod-type or cone-type outer segments characterized by the presence of immunoreactive opsin-, S-antigen- and vitamin A-binding sites. The effector pole may form ribbon-containing synapses on the secondary pineal neurons, and/or neurohormonal terminals on the basal lamina of the pineal nervous tissue.

Applying potassium pyroantimonate (PPA) to electron-microscopic histochemistry, we found in the frog that both effector terminals and photoreceptor outer segments contained a large amount of Capyroantimonate deposit similar to retinal cones and rods. Rods and rod-like pinealocytes contained more deposits than cones. The higher concentration of calcium on the cell membranes of dark pinealocytes in the rat may be connected with their rod-like character. In the frog, a high amount of calcium seemed to be concentrated in the photoreceptor effector terminals, especially around their synaptic ribbons, and in myeloid bodies of the pineal ependyma and retinal pigment epithelium. Calcium was richly found in or around corpora arenacea in the human and rat pineal. It is suggested that the formation of concrements may be connected with the high demand of Ca-exchange of pinealocytes for their receptor and effector membrane functions.

In the rat, lymphocytes were found to migrate through the wall of the vena magna of Galen and to closely contact pinealocytes, presumably to receive immunological information as an additional pineal output.

In earlier investigations, we studied the fine structure of the pineal organ of different vertebrates. Histologically, it was found to represent a special brain tissue, not only by its ontogeny but also by its composition of ependymal/glial cells, neurons and pinealocytes, the latter being photosensory cells with regard to their evolution (VIGH-TEICHMANN and VIGH, 1983; VIGH et al., 1986; VIGH, 1987; VIGHTEICHMANN et al., 1988).

Our immunocytochemical studies revealed two main classes of pineal photoreceptors differing by the antigenicity of their outer segments to antisera raised against opsin, and against S-antigen, a protein characteristic of rods. Rodopsin and/or S-antigen containing cells are regarded as rods (Fig. 1a), the negative ones as cones (VIGH-TEICHMANN and VIGH, 1986; Vigh and Vigh-TeICHMANN, 1988).

We did not find essential differences in the organization of the mammalian and submmamalian pineal organ. The latter cannot be considered as a peripheral gland ("pineal gland"), but it represents a part of the brain. The secretory feature of the pineal organ is due to its neurosecretory activity (1it. see VIGH and Vigh-TeIChmann, 1988). Following the law of neural organization, the hormonal release from the pineal organ is performed by means of "neuroendocrine axon terminals" of pinealocytes, whose terminals are analogous to those of the neurohypophysis. In contrast, pinealocytes containing many granular vesicles - but forming axodendritic synapses by their axons - are not regarded as hormone-producing cells but as pinealocytes disposing of a "common neural output" (Fig. 1b, c). The formation of neurohormonal terminals does not seem to be connected with a regression of the photoreceptor pole, as earlier thought, because pinealocytes with a well-developed photoreceptor outer segment can also display neurohormonal terminals (VIGH and Vigh-TEICHMANN, 1988).

We recently studied pineal calcification, the formation of corpora arenacea in bats and rats (VIGH, 1987; VIGH and Vigh-TeIChMANN, 1988; VIGH et al., 1989a, b). During this study, we observed calcium contents in

\footnotetext{
*Supported by the Hungarian OTKA grant No. 1619 to B. V.
} 
different compartments of the pinealocytes of lower vertebrates. Therefore, in the present work we studied in detail the light and ultrastructural localization of $\mathrm{Ca}$-ions, with special reference to the receptor and effector endings of the pinealocytes and to structures putatively involved in the circulation of this cation. In this respect, we also compared the pinealocytes with retinal photoreceptors.

The possibility of an additional "pineal output", i. e., an information exchange between pinealocytes and the immune system is also here considered.

\section{MATERIAL AND METHODS}

Fifty-five human pineal organs of both sexes received from pathological dissections were embedded in paraffin and/or in Araldite.

Forty CFY (originally Sprague-Dawly) rats of both sexes and six frogs (Rana esculenta) were used for the demonstration of $\mathrm{Ca}$-ions. Some of the material was treated by the Kossa method (RomEIs, 1948), the others by potassium pyroantimonate electronmicroscopic histochemistry (EISENMANN et al., 1979). One group of the animals was parathyroidectomized and maintained for one to two months drinking Ca-enriched tapwater.

For electron microscopy and opsin- and 5HTimmunocytochemistry, six pigeons (Columba domestica) and three lampreys (Lampetra planeri) were sacrificed.

Animals anesthetized with ether or MS 222 were perfused intracardially with $0.5-5 \%$ glutaraldehyde fixative solved in phosphate buffered $4 \%$ paraformaldehyde. The pineal organ, epithalamus and retina were dissected, washed in a buffer, dehydrated in ethanol, and embedded in Araldite. One micron thick sections were stained with toluidine blue-azure II. Ultrathin sections stained with uranyl acetate and lead citrate were examined and photographed in a JEM 6C and OPTON 902 electron microscope.

Opsin immuncytochemistry was performed as described earlier (VIGH and Vigh-TeichmanN, 1988). For data on immuno-electron microscopic demonstration of 5HT, see in VIGH-TEICHMANN and VIGH in the same issue.

\section{RESULTS}

Using pyroantimonate electron cytochemistry, we found that both the effector terminals and photoreceptor outer segments of the frog pineal organ contained a large amount of calcium, similar to retinal cones and rods (Fig. 2). In both the retina and pineal organ, the rods displayed more Ca-pyroantimonate (Ca-PA) deposits than cones. In the light-adapted retinal rod the deposits were found to be localized intracisternally and in the "fissures" of the outer segments. In dark-adapted material prepared under red light $(800-2,000 \mathrm{~nm}, 4 \mathrm{lux})$, the rods contained a high amount of Ca-PA deposits distributed over the entire outer segment (Fig. 2a). At those parts of the retina where the pigment epithelium was detached, the number of $\mathrm{CaPA}$ deposits was strongly decreased. In pineal outer segments phagocytosed into macrophages, a large accumulation of Ca-PA deposits was found (Fig. 2d).

The highest Ca-PA content was present in myeloid bodies. In the well developed myeloid bodies of the lamprey pineal organ, we could distinguish three main parts: 1) loosely arranged endoplasmic reticulum on both sides of the body; 2) a main portion formed by tightly packed membranes; and 3) an inner part of more loosely arranged membranes (Fig. 3a). A similar arrangement was found in the myelod bodies of the frog retina, where the different parts exhibited varying concentrations of Ca-PA deposits (Fig. 3b).

The axon terminals of pineal and retinal photoreceptors also contained a considerable amount of Ca-PA deposits (Fig. 3c). In these terminals, the synaptic ribbons seemed to concentrate calcium on their surfaces.

The light microscopic Kossa technique revealed a higher calcium concentration in the rat pineal organ than in the neighbouring telencephalic tissue. In contrast, the glomeruli of the cerebellum showed a rather high calcium content.

With the PPA method the Ca-PA deposits were found at a lower concentration on the cell membranes of pinealocytes than in arachnoid cells around the acervuli. The corpora arenacea of the arachnoid of parathyroidectomized rats operated on two months before fixation, seemed to be extremely large (Fig. 3d).

Fig. 1. Receptor and effector endings of pinealocytes. a. Opsin immunoreaction (small dots) of the photoreceptor outer segment $(O S)$ of a rod-type pinealocyte of the lamprey, Lampetra planeri. IS inner segment. $\times 16,500$. b. Axo-dendritic synapse (arrow) formed by a pinealocyte of the lizard (Lacerta agilis) on a dendrite $(P)$ of a pineal secondary neuron. $V$ large granular vesicles characteristic of a type of pinealocyte of Lacerta. $\times 48,000$. c. Neurohormonal terminal of a pinealocyte of the pigeon Columba domestica. Asterisk basal lamina of the pineal nervous tissue, $V$ granular vesicles immunoreacting with anti-5HT and immunogold conjugate. $\times 53,000$ 

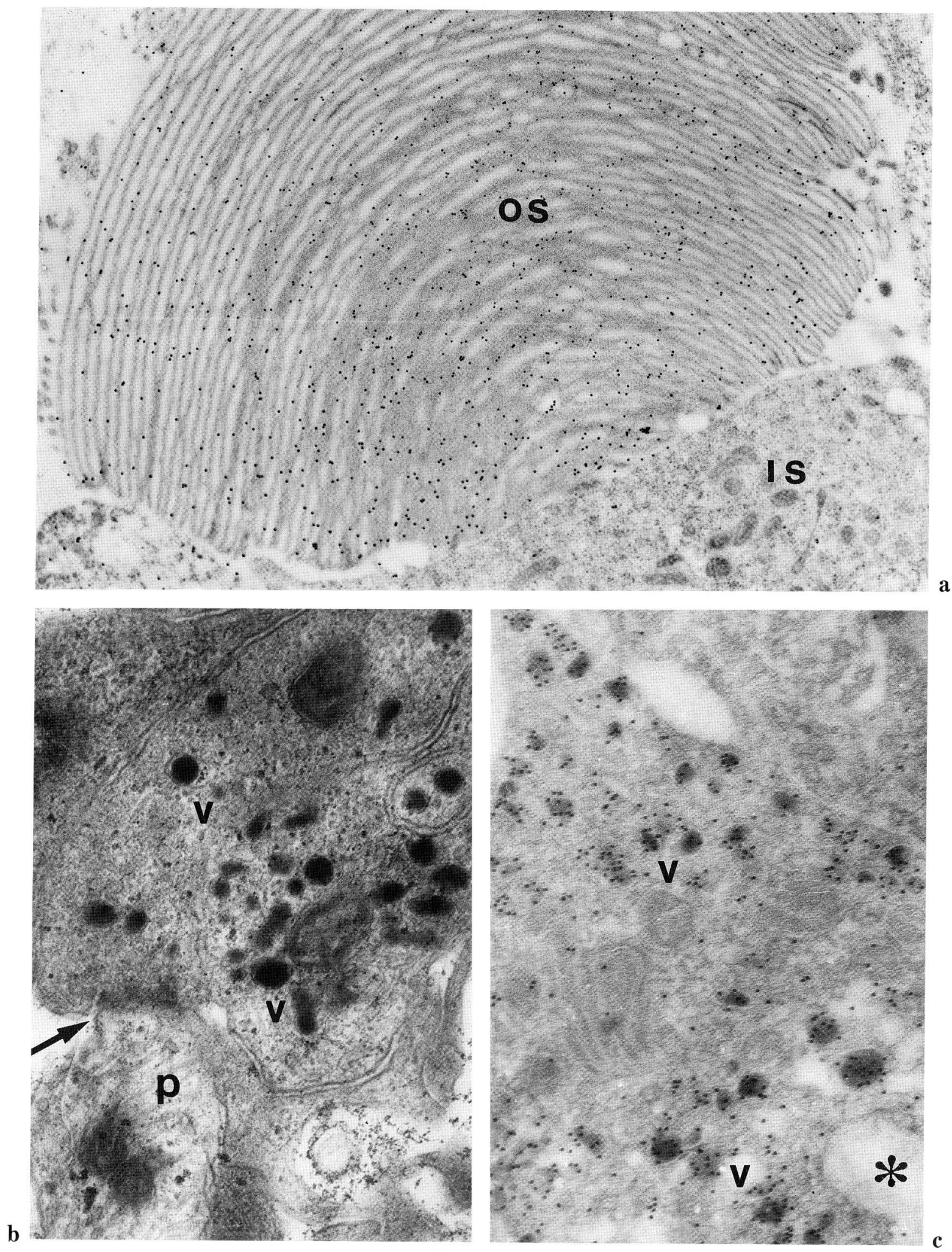

Fig. 1. Legend on the opposite page. 

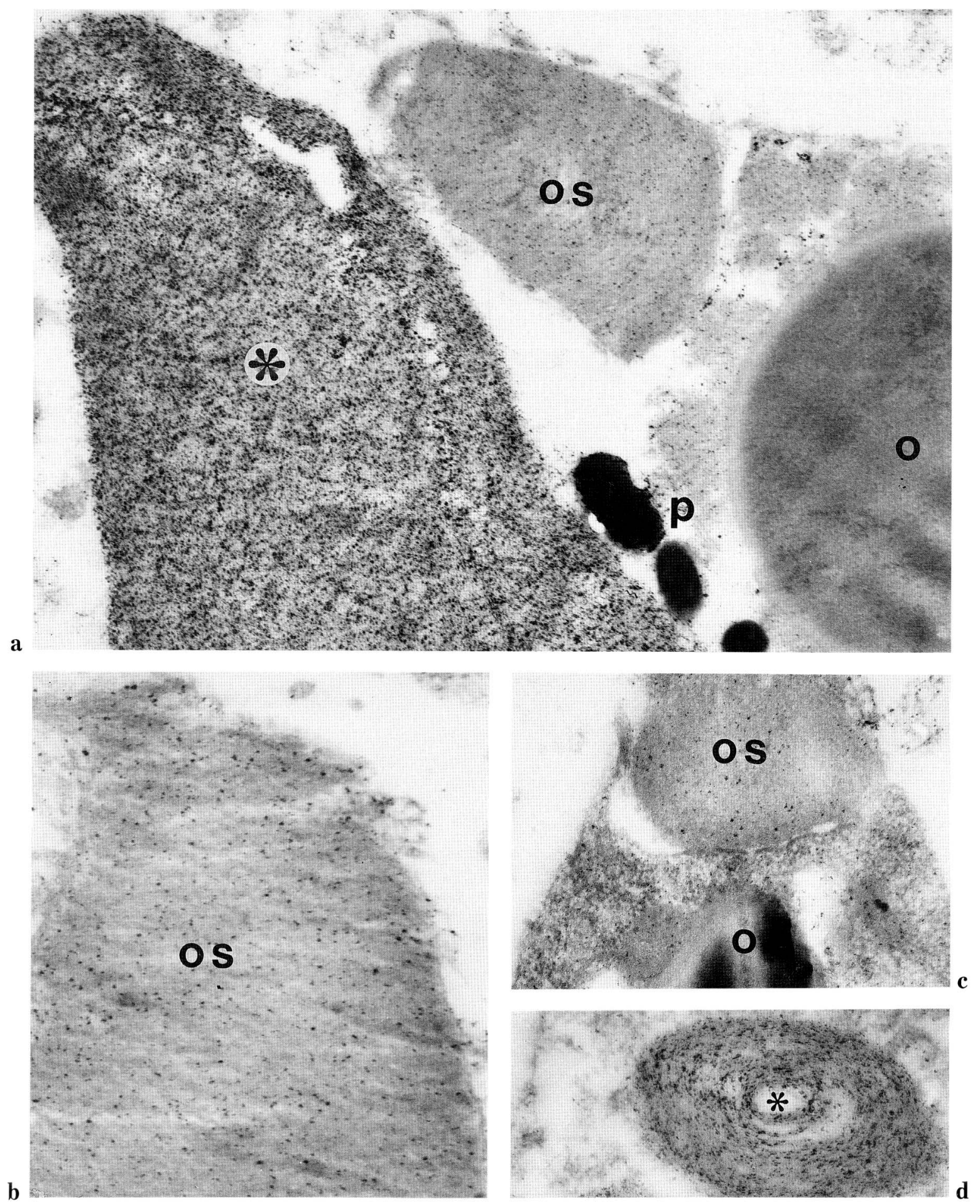

Fig. 2. Localization of Ca-ions in the retinal and pineal photoreceptor outer segments of the frog Rana esculenta. a. The outer segment $(O S)$ of retinal cone containing fine Ca-pyroantimonate deposits, and a rod (asterisk) exhibiting a stronger reaction in animals fixed under red light. $O$ oil droplet of the cone inner segment, $P$ melanin granules of the pigment epithelium. $\times 26,000$. b. The outer segments $(O S)$ of the rod-like pinealocytes of the red light-adapted frog contain more Ca-pyroantimonate deposits than the cone outer segments of the same animal (see Fig. c.). $O$ oil droplet of the cone inner segment. b: $\times 40,000$, c: $\times 29,000$. d. Outer segments taken up by pineal phagocytes are densely covered by Ca-pyroantimonate deposits (asterisk). $\times 40,000$ 
a

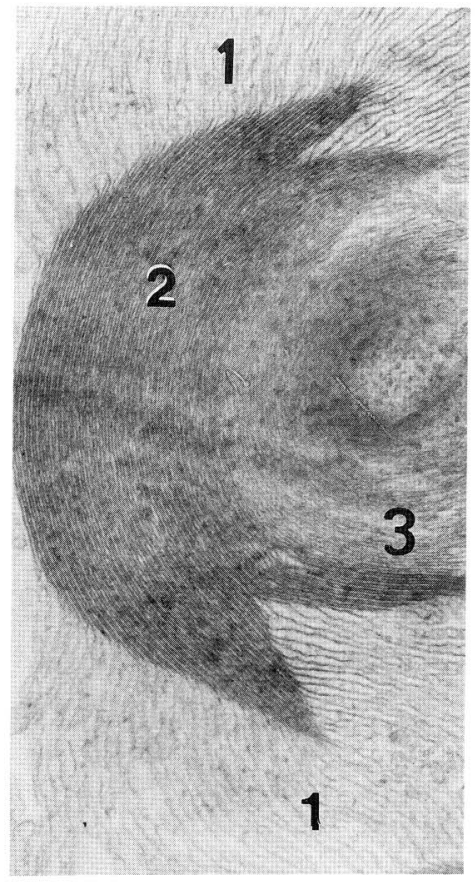

b

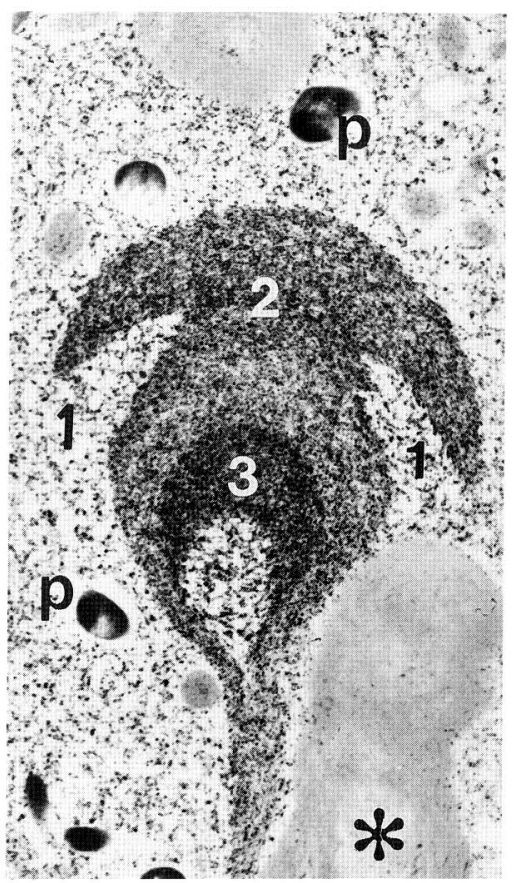

C
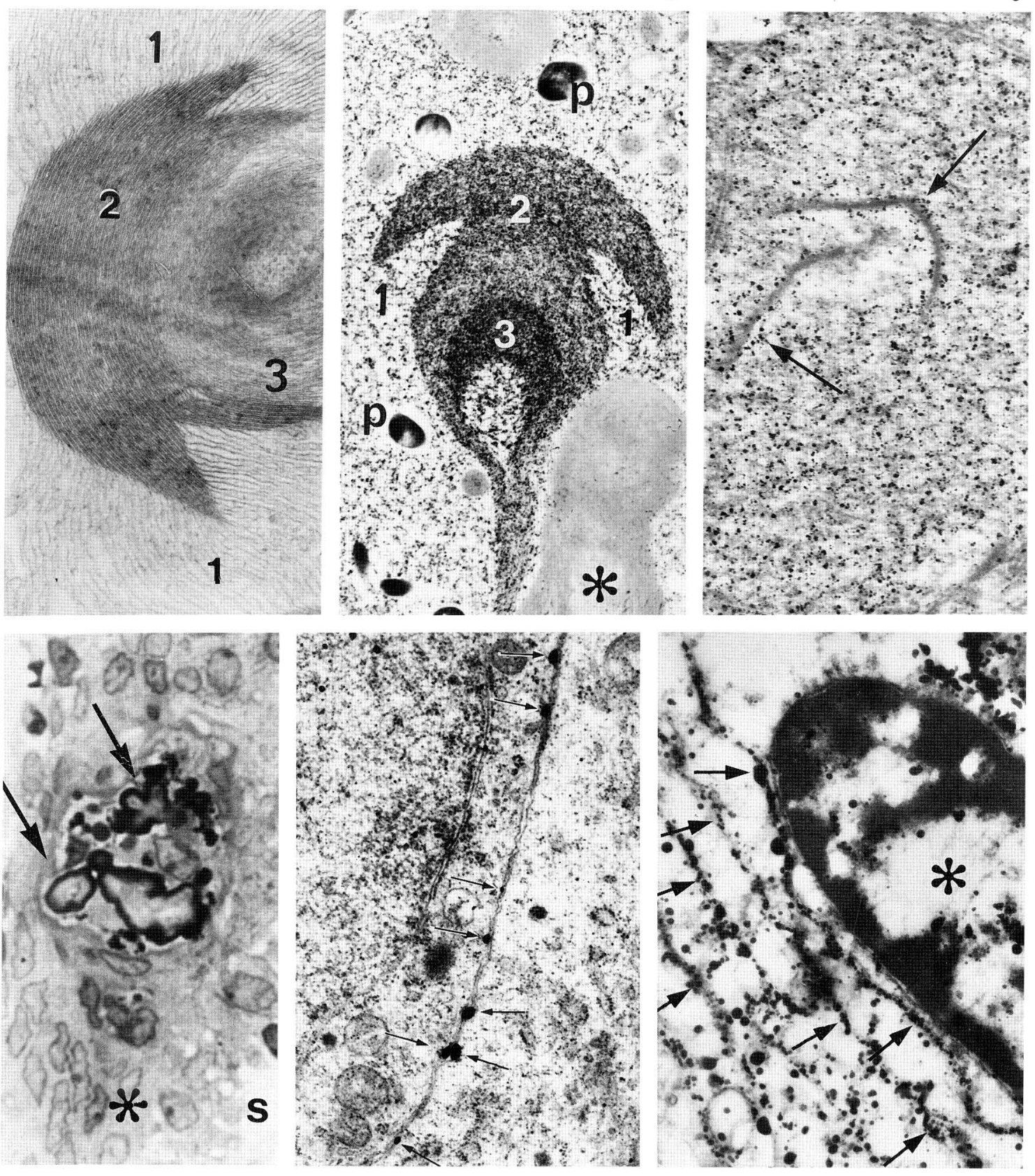

e

Fig. 3. Electron cytochemical localization of Ca-ions in the pineal organ and retina. a. Myeloid bodies display three different parts for the structure of their membranes (1-3). Pineal organ of the lamprey. $\times 14,500$. $\mathbf{b}$. Distribution of Ca-pyroantimonate deposits in the different parts of the myeloid body of the pigment epithelium of the frog retina. The strongest accumulation of Ca-ions is seen in Part 3. $P$ pigment granules. Asterisk: phagocytosed outer segment containing few Ca-pyroantimonate deposits. $\times 11,500$. c. Presynaptic terminal formed by a retinal photoreceptor cell; the terminal contains many Ca-pyroantimonate deposits. Arrows synaptic ribbons. $\times 24,000$. d. Meningeal acervulus (double arrows) above the pineal organ of rat parathyroidectomized two months before sacrifice. Asterisk: arachnoid, $S$ subarachnoid space. $\times 1,050$. e. Light (right) and dark (left) pinealocyte of the rat. Dark pinealocytes possess more Ca-pyroantimonate deposits on the plasmalemma than light ones (arrows). $\times 4,600$. f. Electron microscopic demonstration of Ca-ions by pyroantimonate cytochemistry in the human arachnoid. In the upper right corner: marginal zone of an acervulus. Note the Ca-pyroantimonate deposits alongside the plasmalemma of the arachnoid cells (arrows), Asterisk: nucleus of an arachnoid cell. $\times 16,500$ 
Dark pinealocytes of unoperated rat pineals contained slightly more Ca-PA deposits than the membranes of light pinealocytes (Fig. 3e).

Calcium could be demonstrated on and around the human pineal acervuli as well, by light microscopic Kossa and electron microscopic PPA methods. The commissural and intrapineal concrements exhibited a higher calcium content than the arachnoid acervuli. Electron-microscopically the Ca-pyroantimonate deposits were found-as in the rat-in the intercel- lular spaces around the concrements (Fig. 3f).

As signs of an additional pineal connection, lymphocytes were present close by the rat pineal organ in the wall of the great vein of Galen. They were arranged in groups below the vessel (Fig. 4a, b).

The lymphoid elements established close contact with pinealocytes (Fig. 4c). On the inner surface of the vein of Galen lymphoid cells were accumulated and the endothelium was thickened at the side contacting the pineal organ (Fig. $4 \mathrm{~b}$ ).
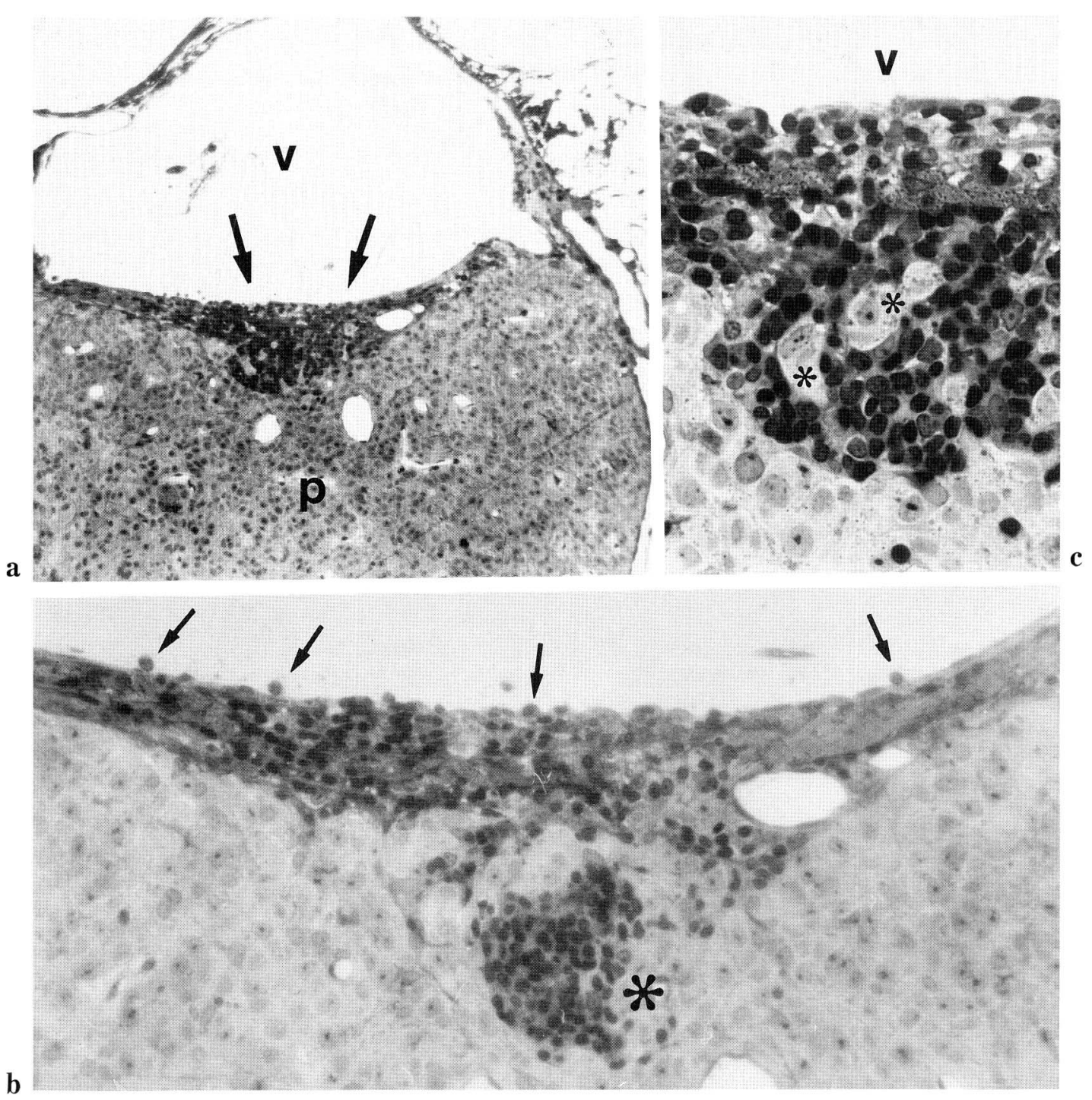

Fig. 4. Lymphoid tissue in the rat pineal organ. Toluidin blue staining. a. Cross section of the pineal organ $(P)$ and the great vein of Galen $(V)$. arrows point to accumulation of lymphoid cells on the endothelium. $\times 185$. b. Lymphoid cells in the wall of the vein of Galen, in the arachnoid separating the vein from the pineal organ and inside the pineal organ (asterisk). Structures on the wall of the vein (at arrows) indicate the migration of lymphoid cells across the wall of the vessel. $\times 300$. c. Lymphoid cells in close contact with pinealocytes (asterisks). $\times 520$ 


\section{DISCUSSION}

As we have seen, both the receptor and effector terminals of the frog photoreceptor pinealocytes contain a large amount of calcium, similar to retinal cones and rods. This result is in accord with the well known significance of calcium and its exchanges across the membranes of the retinal photoreceptors (lit. see: KAUPP and $\mathrm{KOCH}, 1986$ ). Further, our data are in agreement with the findings of $\mathrm{UECK}$ and coworkers (1987) who described natrium-kalium ATPase and calcium ATPase activity in pinealocytes of the frog. PocheT and coworkers (1987) demonstrated calcium binding protein in the pineal and retina of several vertebrates. Both papers report differences in the reaction of cones and rods or coneand rod-like pinealocytes. We also found differences in the calcium content itself in these cells: rod-type pinealocytes and rod outer segments of the retina contained more calcium than cone outer segments. Calcium has been demonstrated in the gerbil pineal organ by KRSTIC $(1985,1986)$ and by WeLSH $(1985)$ by means of pyroantimonate histochemistry. KRSTIC (1986) found calcium ATPase along the plasmalemma of pinealocytes in the gerbil, an enzyme that uses the energy of ATP hydrolysis to pump calcium out of the cell (see also: UECK et al., 1987).

The presence of calcium inside the pinealocytes was thought to be related to the production of concrements (LUKASZYK and REITER, 1975; JAPHA et al., 1976; KRSTIC, 1985, 1986; a. o.). The present findings suggest that a higher concentration of calcium in the pineal organ may be due to the receptor and effector membrane functions of the pineal. Perhaps the high number of tightly packed pinealocytes in the mammalian and human pineal and actively removing calcium is a further reason for the frequent formation of corpora arenacea in mammals (Fig. 5).

The presence of lymphoid cells in the pineal organ could be explained as morphological sign of an additional pineal output to the immune system. Lymphocytes present in the rat pineal organ were already described by UEDE and coworkers (1981) as T-lymphocytes. The authors supposed that the pineal organ might have some role in an immune response within the brain. Lymphoid tissue in the pineal is a common finding in birds. OLAH and GLICK (1984) named the mixture of pinealocytes and lymphoid cells "lymphopineal tissue" in the chicken. There is morphological evidence for a migration of lymphoid cellls through the wall of the great vein of Galen,

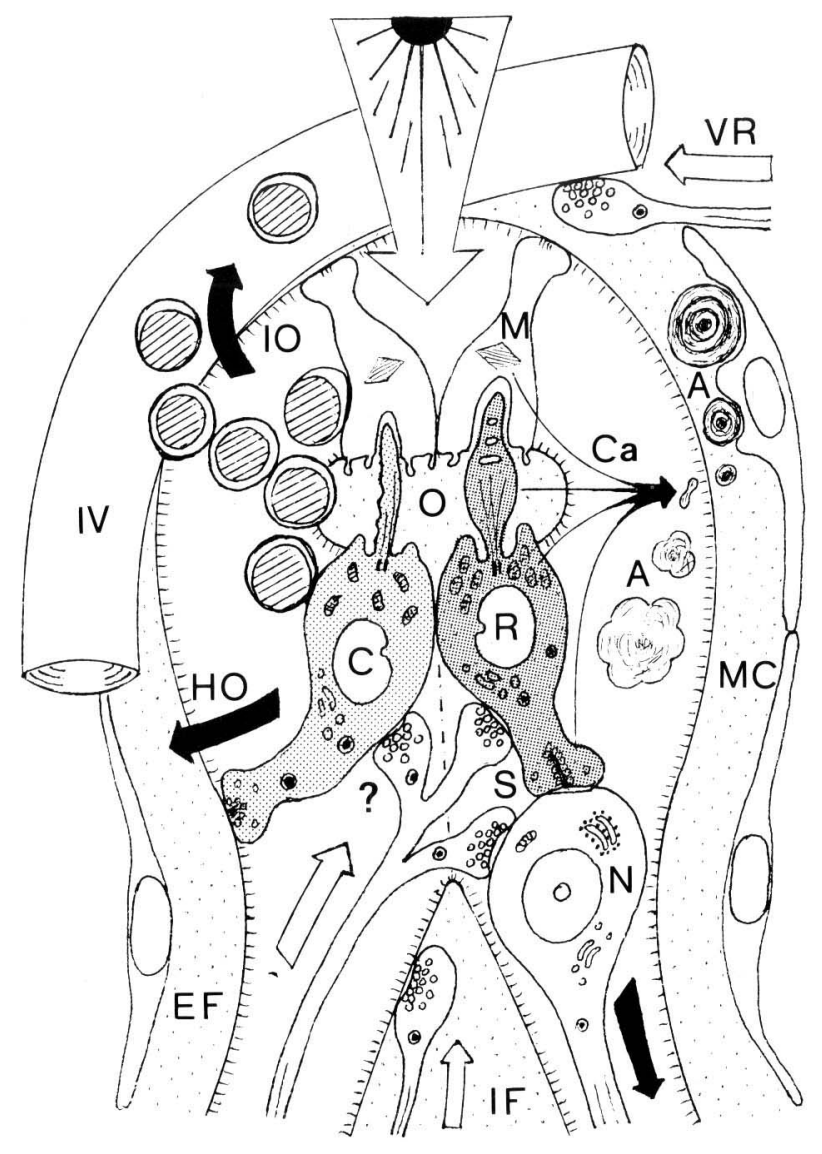

Fig. 5. Schematic drawing summarizing our results concerning the pinealocytes forming receptor and effector endings. Black arrows indicate pineal "outputs", white arrows various "inputs". The large arrow with the sunsymbol indicates light percepted by the pinealocytes. $A$ acervuli, $C$ cone-type pinealocyte, $C a$ calcium ions, $E F$ external cerebrospinal fluid space, $H O$ hormonal "output" by the neurohormonal terminal of the pinealocyte, $I F$ internal cerebrospinal fluid space, $I O$ immunological "output" by the presumed migration of lymphocytes across the wall of the internal cerebral vein-system $(I V), M$ myeloid bodies in pineal glial cells, $M C$ meningeal cells, $N$ secondary pineal nerve cell, $O$ outer segments of the pinealocytes, $R$ rod-type pinealocyte, $V R$ vasoregulative innervation.

which is tightly connected with the pineal in rats. This way may represent an information channel between the pineal organ and the immune system. By the contact between pinealocytes and lymphocytes, the immune system may receive information in order to be able to recognize pineal-neuronal elements. 


\section{REFERENCES}

Eisenmann, D. R., S. Ashrafi and A. Neiman: Calcium transport and the secretory ameloblast. Anat. Rec. 193: 403-422 (1979).

JAPHA, J. L., T. J. EDER and E. D. Goldsmith : Calcified inclusions in the superficial pineal gland of the Mongolian gerbil, Meriones unguiculatus. Acta Anat. 94:533544 (1976).

KAUPP, U. B. and K. W. Koch: Significance of changes in intracellular $\mathrm{Ca}_{2}{ }^{+}$for the mechanism of signal transduction in vertebrate rod cells. In: (ed. by) H. STIEvE: The molecular mechanism of photoreception. SpringerVerlag, Berlin-Heidelberg-New York, 1986 (p. 93-107).

KRISTIC, R.: Ultrustructural localization of calcium in the superficial pineal gland of the Mongolian gerbil. J. Pineal Res. 2: 21-38 (1985).

: Pineal calcification: its mechanism and significance. J. Neural Trans. (Suppl.) 21: 415-432 (1986).

LUKAsZYK, A. and R. J. ReITER: Histophysiological evidence for the secretion of polypeptides by the pineal gland. Amer. J. Anat. 143: 451-464 (1975).

OLAH, I. and B. GLICK: Lymphopineal tissue in the chicken. Devel. Comp. Immunol. 8: 855-862 (1984).

Pochet, R., J. P. Collin, A. Roman, P. Brisson and B. PASTELS: Immunoreactivity of calbindin-27 $\mathrm{kDa}$ (a calcium binding protein) in vertebrate pineal and retina. In: (ed. by) G. P. Trentini, C. De Gaetani and P. PEvET: Fundamentals and clinics in pineal research. Raven Press. New York, 1987 (p. 57-60).

RomeIs, B.: Mikroskopische Technik. Leibnitz, München, 1948.

UECK, M., M. UMAR, H. UMAR and A. HACH: $\mathrm{Na}^{+}-\mathrm{K}^{+}$ATPase and $\mathrm{Ca}^{++}$-ATPase activity in the pineal organ of the frog (Rana esculenta). In: (ed. by) G. P. TRENTINI, C. De Gaetani and P. Pevet: Fundamentals and clinics in pineal research. Raven Press, New York, 1987 (p. 5356).

Uede, T., Y. Ischil, A. Matsuura, I. Shimogawara and K. KIKUCHI : Immunohistochemical study of lymphocytes in rat pineal gland: selective accumulation of T-lymphocytes. Anat. Rec. 199: 239-247 (1981).
VIGH, B.: Comparative cytomorphology of pineal organs. Dr. Sci. Thesis. Hung. Acad. Sci. Budapest, 1987 (p. 1231).

Vigh, B. and I. Vigh-TeichmanN: Three types of photoreceptors in the pineal and frontal organs of frogs: Ultrastructure and opsin immunoreactivity. Arch. Histol. Jap. 49: 495-518 (1986).

- Comparative neurohistology and immunocytochemistry of the pineal complex with special reference to CSF-contacting neuronal structures. Pineal Res. Rev. 6: 1-65 (1988).

Vigh, B., I. Vigh-Teichmann, I. Reinhardt, A. Szêl and T. VAN VeEn: Opsin immunoreaction in the developing and adult pineal organ. In: (ed. by) D. GUPTA and R. J. REITER: The pineal gland during development: from fetus to adult. Croom-Helm, London-Sydney, 1986 (p. 31-42).

Vigh, B., I. Vigh-Teichmann and B. Aros: Pineal corpora arenacea produced by arachnoid cells in the bat Myotis blythi oxygnathus. Z. Mikrosk-Anat. Forsch. 103: 36-45 (1989a).

Vigh, B., I. Vigh-Teichmann, T. Heinzeller and I. TUTTER: Meningeal calcification of the rat pineal organ. Finestructural localization of calcium ions. Histochemistry $91: 161-168$ (1989b).

Vigh-TeichmanN, I. and B. Vigh: The system of cerebrospinal fluid contacting neurons. Arch. Histol. Jap. 46: 427-468 (1983).

- The pinealocyte: its ultrastructure and opsin immunocytochemistry. Adv. Pineal Res. 1: 31-40 (1986).

WeLSH, M. G.: Pineal calcification: Structural and functional aspects. Pineal Res. Rev. 3: 41-68 (1985).

WeLSh, M. G. and R. J. Reiter: The pineal gland of the gerbil, Meriones unguiculatus. Cell Tiss. Res. 193: 323336 (1978).

Dr. Béla VIGH

2nd Department of Anatomy

Semmelweis University Medical School

Tüzoltó utca 58.

1094 Bundapest IX

Hungary 